\title{
A Radiorespirometric Study on the Contribution of the Hexose Monophosphate Pathway to Glucose Metabolism in Candida utilis CBS 621 Grown in Glucose-limited Chemostat Cultures
}

\author{
By PETER M. BRUINENBERG, $\dagger$ JOHANNES P. VAN DIJKEN AND \\ W. ALEXANDER SCHEFFERS* \\ Laboratory of Microbiology, Delft University of Technology, Julianalaan 67A, \\ NL-2628 BC Delft, The Netherlands
}

(Received 22 May 1985; revised 15 August 1985)

\begin{abstract}
A radiorespirometric study of glucose metabolism in Candida utilis CBS 621 was done using glucose-limited chemostat cultures growing at a dilution rate of $0 \cdot 1 \mathrm{~h}^{-1}$ with ammonium or nitrate as the nitrogen source. From a steady-state analysis of ${ }^{14} \mathrm{CO}_{2}$ yields from $\left[1-{ }^{1+} \mathrm{C}\right]-$ and [6${ }^{14} \mathrm{C}$ glucose supplied in the medium feed it appeared that during growth with nitrate the flow of glucose through the hexose monophosphate (HMP) pathway was much higher than during growth with ammonium as the nitrogen source. The same phenomenon was apparent from an analysis of the rate of ${ }^{14} \mathrm{CO}_{2}$ production after administration of small amounts of labelled glucose to samples withdrawn from steady-state cultures. Additionally, these experiments revealed not only that the initial fraction of glucose 6-phosphate routed into the HMP pathway increases, but also that recycling of hexose phosphates via this pathway increases when nitrate is used as the nitrogen source. From a quantitative analysis of the results it is concluded that the contribution of the HMP pathway to glucose metabolism is close to the theoretical minimum required to cover the NADPH requirement for biosynthesis.
\end{abstract}

\section{INTRODUCTION}

Theoretical calculations reveal that in yeasts the NADPH requirement for biomass formation is strongly dependent on the carbon and nitrogen sources used for growth (Bruinenberg $e t$ al., $1983 a$ ). Enzyme studies indicated that in Candida utilis especially the hexose monophosphate (HMP) pathway, and possibly NADP+-linked isocitrate dehydrogenase, are the major sources of NADPH (Bruinenberg et al., 1983b). However, a strict correlation between the observed enzyme activities of the NADPH-producing pathways and the theoretical NADPH requirement for biomass formation was not detected. It was therefore questioned whether the observed differences in enzyme activities in relation to the various growth conditions indeed reflect variations in operational activities in vivo (Bruinenberg et al., 1983b).

Insight into carbon flows in vivo through various metabolic pathways may be obtained via analysis of ${ }^{14} \mathrm{CO}_{2}$ production from glucose, labelled specifically at different positions in the carbon skeleton (Wang, 1972). One of the difficulties in the interpretation of radiorespirometric data reported in the literature is that for these studies batch cultures are used routinely. In batch culture different organisms exhibit different growth rates; moreover, for each organism the growth rate is dependent on the carbon and nitrogen sources used for growth. Since the rate of NADPH consumption and production is related to the growth rate, a comparative study of glucose metabolism in different organisms growing in batch cultures with different nitrogen sources may lead to misleading conclusions. Surprisingly, radiorespirometric studies with yeasts

+ Present address: AVEBE, Klaas Nieboerweg 12, NL-9607 PN Foxhol, The Netherlands. 
growing in continuous culture have not been done so far. Although Mian et al. (1974) and Dawson et al. (1976) used chemostat-grown cells, the actual radiorespirometric experiments described by these authors were done by pulse-labelling samples taken from the chemostat; thus the experimental conditions resemble those of batch cultures.

In this paper a radiorespirometric study is presented in which radioactively labelled glucose was administered directly to glucose-limited chemostat cultures of $C$. utilis, either in a constant substrate feed, without disturbance of the steady-state, or as a pulse to small samples withdrawn from steady-state cultures. An attempt is made to evaluate the quantitative importance of the HMP pathway in glucose metabolism in relation to the growth conditions. The results are compared with theoretical and enzymic data on the contribution of the HMP pathway in glucose metabolism in yeasts (Bruinenberg et al., 1983a,b).

\section{METHODS}

Micro-organism and growth conditions. Candida utilis CBS 621 was maintained on malt agar slopes. The organism was grown at a dilution rate of $0.1 \mathrm{~h}^{-1}$ and $30^{\circ} \mathrm{C}$ in a laboratory fermenter with a working volume of 1 litre of the type described by Harder et al. (1974). The dissolved-oxygen tension was recorded with a steam-sterilizable Clarktype electrode and was always more than $80 \%$ of air saturation. The flow rate of air into the fermenter was $200 \mathrm{ml} \mathrm{min}-1$. The $\mathrm{pH}$ was controlled at 4.0 by the automatic addition of $1 \mathrm{M}-\mathrm{KOH}$ or $0.5 \mathrm{M}-\mathrm{H}_{2} \mathrm{SO}_{4}$. The mineralsalts medium described by Bruinenberg et al. (1983b) was used. It contained a fixed glucose concentration of 5.5 or $6.6 \mathrm{mM}$ for growth with ammonium or nitrate, respectively. In some experiments potassium formate was added to a final concentration of $20 \mathrm{~mm}$. Dry weight of cultures, and formate and glucose concentrations, were determined according to Bruinenberg et al. (1985a).

Radiorespirometry. Radiorespirometric studies in chemostat cultures were done by switching, without disturbance of the steady-state, from the normal unlabelled feed to a feed of the same medium containing labelled glucose with a specific activity of $0.5-1 \mu \mathrm{Ci} \mathrm{mmol}^{-1}\left(18.5-37 \mathrm{kBq} \mathrm{mmol}^{-1}\right)$. Gas sampling and determination of label incorporated in biomass were done as described below. Dissolved $\mathrm{CO}_{2}$ in the culture fluid was determined by collecting the overflow of the chemostat for $3 \mathrm{~min}$ in a closed vial containing a centre well in which there was $1 \mathrm{ml}$ of $1 \mathrm{M}-\mathrm{KOH}$. Dissolved $\mathrm{CO}_{2}$ in the sample was then released by acidification to $\mathrm{pH} 1.0$ with $0.5 \mathrm{ml} 5 \mathrm{M}-\mathrm{H}_{2} \mathrm{SO}_{4}$ and incubation of the vial for $30 \mathrm{~min}$ on a rotatory shaker at 100 r.p.m. A $0.5 \mathrm{ml}$ sample was withdrawn from the centre well and counted in $18 \mathrm{ml}$ Aquasol scintillator fluid. Dissolved $\mathrm{CO}_{2}$ accounted for less than $2 \%$ of the total amount of label added. It was therefore not included in the calculations.

Pulse-labelling was done in $5 \mathrm{ml}$ samples (collection time $3 \mathrm{~min}$ ) taken from the overflow of a steady-state culture. The samples were immediately transferred to small Kluyver flasks (see Robertson \& Kuenen, 1984) with a working volume of $20 \mathrm{ml}$. After incubation for $2 \mathrm{~min}$ at $30^{\circ} \mathrm{C}$ and gassing with preheated, water-saturated and $\mathrm{CO}_{2}$-free air at a flow rate of $200 \mathrm{ml} \mathrm{min}-1,3 \mu \mathrm{mol}$ labelled glucose of specific activity approximately $5 \mu \mathrm{Ci} \mu \mathrm{mol}^{-1}\left(185 \mathrm{kBq} \mu \mathrm{mol}^{-1}\right)$ was added. $\mathrm{CO}_{2}$ in the inflow air was removed by passing the air through a column filled with Carbosorb. ${ }^{14} \mathrm{CO}_{2}$ production and incorporation of label in biomass were determined as described below. Under the experimental conditions addition of $\mathrm{NaH}^{14} \mathrm{CO}_{3}$ resulted in $90 \%$ and $100 \%$ release of the label after 30 and $60 \mathrm{~s}$, respectively. Addition of carbonic anhydrase did not accelerate this release. At a fixed working-volume of $5 \mathrm{ml}$, doubling of the biomass concentration resulted in a doubling of the rate of $\mathrm{CO}_{2}$ release from [U-14 C]glucose.

$\mathrm{CO}_{2}$ absorption. In experiments with continuous substrate feeding and in pulse-labelling experiments the same device was used for the collection of $\mathrm{CO}_{2}$. The apparatus consisted of copper tubing (inside diameter $1.5 \mathrm{~mm}$ ) with two brass three-way valves. With the first valve the gas flow could be directed either towards a $10 \mathrm{M}-\mathrm{KOH}$ solution or to a pair of absorption vials. By way of the second valve the gas flow could be switched from one absorption vial to the other. The $\mathrm{CO}_{2}$ absorption vials were $20 \mathrm{ml}$ glass scintillation vials containing $8 \mathrm{ml} 30 \%(\mathrm{v} / \mathrm{v}) 2-$ aminoethanol in 2-methoxyethanol.

Liquid scintillation counting. After $\mathrm{CO}_{2}$ absorption, $12 \mathrm{ml}$ of a toluene-based scintillator containing $5 \mathrm{~g} 2,5-$ diphenyloxazole (PPO) $1^{-1}$ and $0 \cdot 1 \mathrm{~g} p$-bis( $o$-methylstyryl)benzene (bis-MSB) $1^{-1}$ was added to the absorption vials. In the experiments with continuous substrate feeding, incorporation of label into biomass was determined by filtration through membrane filters (Millipore, $0.45 \mu \mathrm{m}$ pore size, $25 \mathrm{~mm}$ diameter) of $5 \mathrm{ml}$ samples taken from the overflow of the chemostat culture. Filtered biomass was washed once with $5 \mathrm{ml}$ water. The filter was placed at the bottom of a standard $20 \mathrm{ml}$ glass scintillation vial and $15 \mathrm{ml}$ Emulsifier Scintillator 299 was added. After clearing of filter and biomass, radioactivity was counted. Self-absorption of photons by biomass on the filter was beyond the limit of detection. Radioactivity incorporated into biomass during pulse-labelling experiments was determined after depletion of glucose from the suspension. To $15 \mathrm{ml}$ Emulsifier Scintillator 299 samples of 50 or $100 \mathrm{ul}$ were added. Radioactivity of aqueous solutions was determined by counting appropriate volumes of 
samples in $15 \mathrm{ml}$ Emulsifier Scintillator 299. Liquid scintillation counting was done with a Beckman LS 3801 benchtop counter.

Calculations. For calculation of the relative contribution of the HMP pathway to glucose metabolism, the formulae of Wang \& Krackov (1962) and of Katz \& Wood (1963) were used. According to Wang \& Krackov (1962), the fraction of glucose metabolized via the HMP pathway $\left(G_{p}\right)$ can be calculated with the formula $G_{p}=$ $\left(C_{1}-C_{6}\right) /\left(1-C_{6}\right)$, whereas Katz \& Wood (1963) calculated the fraction (PC) with the formula PC $=\left(C_{1}-\right.$ $\left.\mathrm{C}_{6}\right) /\left(3-2 \mathrm{C}_{1}-\mathrm{C}_{6}\right) \cdot \mathrm{C}_{1}$ and $\mathrm{C}_{6}$ represent the fractions of ${ }^{14} \mathrm{CO}_{2}$ produced from $\left[1-{ }^{14} \mathrm{C}\right]-$ and $\left[6-{ }^{14} \mathrm{C}\right] \mathrm{glucose}$, respectively. The term $G_{p}$ of $W$ ang \& Krackov (1962) refers only to the fraction of glucose that has initially been routed into the HMP pathway to give rise to $\mathrm{CO}_{2}$ and pentose phosphates (equation 1). $\mathrm{G}_{\mathrm{p}}$ may be subject to error since recycling of pentose phosphates to glucose 6-phosphate and glyceraldehyde 3-phosphate (equation 2) is neglected. As a result of recycling, dilution of label in the administered $\left[1-{ }^{14} \mathrm{C}\right]$ glucose does occur. Katz \& Wood (1963) therefore based their formula on equation (3), the sum of equations (1) and (2). Note that glucose 6phosphate can also be completely oxidized to $\mathrm{CO}_{2}$, yielding 12 NADPH (equation 4), when the enzyme fructose1,6-bisphosphatase is active during growth with glucose (Bruinenberg et al., 1983a).

3 Glucose 6-phosphate $+6 \mathrm{NADP}^{+} \rightarrow 3 \mathrm{CO}_{2}+3$ pentose phosphate $+6 \mathrm{NADPH}+6 \mathrm{H}^{+}$

3 Pentose phosphate $\rightarrow 2$ glucose 6-phosphate +1 glyceraldehyde 3-phosphate

1 Glucose 6-phosphate $+6 \mathrm{NADP}^{+} \rightarrow 3 \mathrm{CO}_{2}+6 \mathrm{NADPH}+6 \mathrm{H}^{+}+1$ glyceraldehyde 3-phosphate

1 Glucose 6-phosphate $+12 \mathrm{NADP}^{+} \rightarrow 6 \mathrm{CO}_{2}+12 \mathrm{NADPH}+12 \mathrm{H}^{+}$

Labelled substrates. All labelled substrates were obtained from NEN as dry powder, except for $\left[3,4-{ }^{14} \mathrm{C}\right] \mathrm{glucose}$ which was in ethanolic solution. Ethanol was removed by repeated cycles of evaporation to dryness at $80^{\circ} \mathrm{C}$ and redissolving in water, until no ethanol was detectable with the colorimetric assay of Verduyn et al. (1984).

Chemicals. Emulsifier Scintillator 299 was from Packard. Aquasol scintillator fluid and bis-MSB were from NEN and Carbosorb (soda lime, 10-16 mesh) was from BDH. All other chemicals were from Merck.

\section{RESULTS}

Yields of ${ }^{14} \mathrm{CO}_{2}$ from a constant feed of labelled glucose to steady-state cultures

The release of ${ }^{14} \mathrm{CO}_{2}$ and the incorporation of label into biomass upon continuous administration of [ $\left.\mathrm{U}^{-14} \mathrm{C}\right] \mathrm{glucose}$, without disturbance of the steady-state, to a glucose-limited chemostat culture of Candida utilis grown with ammonium as the nitrogen source, is depicted in Fig. 1. The ${ }^{14} \mathrm{CO}_{2}$ recovered in the gas phase slowly increased during the first hours of the experiment. After approximately $3 \mathrm{~h}$ the amount of ${ }^{14} \mathrm{CO}_{2}$ produced per unit time was virtually constant. Variations observed were due to small changes in the $\mathrm{pH}$ of the culture as a result of the automatic $\mathrm{pH}$ adjustment of the fermenter system. Since in the steady-state the rate of $\mathrm{CO}_{2}$ production is constant, the observed kinetics of ${ }^{14} \mathrm{CO}_{2}$ release in the gas phase are a function of the geometry of the fermenter (culture volume versus headspace volume) and the mode of aeration which determines the holdup of $\mathrm{CO}_{2}$ in the fermenter system. Biomass in the culture

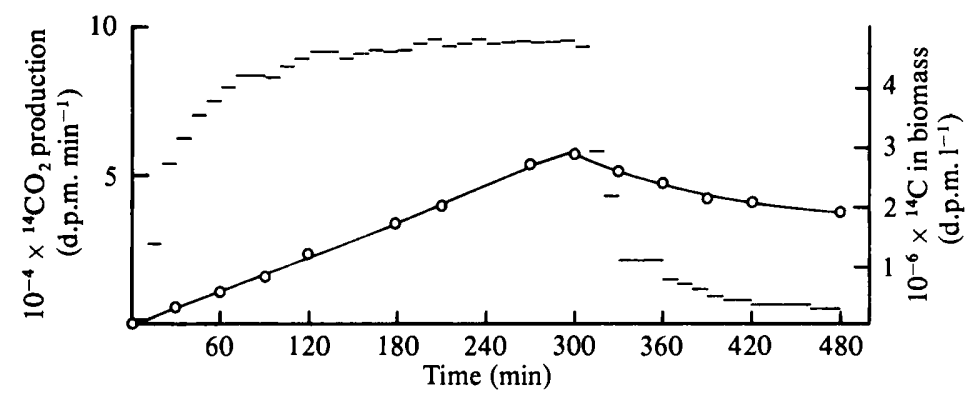

Fig. 1. Production of ${ }^{14} \mathrm{CO}_{2}(-)$ and incorporation of ${ }^{14} \mathrm{C}$ into biomass $(\mathrm{O})$ upon continuous substrate feeding with [ $\left.\mathrm{U}^{-14} \mathrm{C}\right]$ glucose for $5 \mathrm{~h}$ in a glucose-limited chemostat culture of C. utilis CBS 621 , grown at $D=0.1 \mathrm{~h}^{-1}$ with ammonium as the nitrogen source. After $5 \mathrm{~h}$, the radioactive feed was replaced by unlabelled feed. The length of the lines representing the rate of ${ }^{14} \mathrm{CO}_{2}$ production corresponds to the time interval during which ${ }^{14} \mathrm{CO}_{2}$ was collected. 
Table 1. Recovery of ${ }^{14} \mathrm{CO}_{2}$ from labelled glucose during continuous substrate feeding to

$$
\text { C. utilis CBS } 621
$$

Glucose-limited chemostat cultures were grown at $D=0 \cdot 1 \mathrm{~h}^{-1}$ with carbon and nitrogen sources as indicated. Values given are the mean from two or three separate experiments; maximum deviation from the mean was between 2 and $3 \%$. Cell yields are expressed as g dry wt (g glucose $)^{-1}$.

\begin{tabular}{lccc} 
& \multicolumn{2}{c}{ Fraction of label recovered during growth on: } & Glucose + formate \\
Labelled substrate & Ammonium & Nitrate & 0.23 \\
{$\left[\mathrm{U}^{-1} \mathrm{C}\right]$ Glucose } & 0.40 & 0.47 & 0.32 \\
{$\left[1^{-14} \mathrm{C}\right]$ Glucose } & 0.33 & 0.59 & 0.06 \\
{$\left[6^{-14} \mathrm{C}\right]$ Glucose } & 0.18 & 0.24 & 0.69 \\
Cell yield & $0.5]$ & 0.42 &
\end{tabular}

Table 2. Ratio $\mathrm{C}_{1} / \mathrm{C}_{6}$ of ${ }^{14} \mathrm{CO}_{2}$ yields and percentage of glucose oxidized in the HMP pathway by C. utilis CBS 621

The ratio $\mathrm{C}_{1} / \mathrm{C}_{6}$ of ${ }^{1+} \mathrm{CO}_{2}$ yields from $\left[1{ }^{-1+} \mathrm{C}\right]$ and $\left[6^{-1+} \mathrm{C}\right]$ glucose was calculated from the data in Table 1. The percentage of glucose oxidized in the HMP pathway was calculated according to the formulae of Wang \& Krackov (1962) $\left(\mathrm{G}_{\mathrm{p}}\right)$ and Katz \& Wood (1963) (PC).

$\begin{array}{lccc} & \overbrace{\text { Ammonium }} & \text { Nitrate } & \text { Glucose + formate } \\ \text { Ratio } C_{1} / C_{6} & 1 \cdot 8 & 2 \cdot 5 & 5 \cdot 3 \\ \text { Percentage of glucose } & & & \\ \text { oxidized in HMP pathway: } & 18 & 46 & 27 \\ \mathrm{G}_{\mathrm{p}} \times 100 \% & 7 & 21 & 11 \\ \mathrm{PC} \times 100 \% & & & \end{array}$

gradually became more labelled during the experiment. The recovery of label in gas phase and biomass was between 98 and $102 \%$. Upon shifting from the radioactive feed to an unlabelled feed, ${ }^{14} \mathrm{CO}_{2}$ production by the culture decreased sharply but did not become zero. As long as radioactive biomass was present in the culture, ${ }^{14} \mathrm{CO}_{2}$ production was detectable. The decrease of radioactivity in biomass upon the shift, after $5 \mathrm{~h}$, to the unlabelled feed (Fig. 1) is therefore not only a result of washout, but is also due to oxidation of labelled biomass constituents.

Table 1 summarizes the ${ }^{14} \mathrm{CO}_{2}$ yields from $\left[\mathrm{U}-{ }^{14} \mathrm{C}\right]-,\left[1-{ }^{14} \mathrm{C}\right]-$ and $\left[6-{ }^{14} \mathrm{C}\right]$ glucose in glucoselimited chemostat cultures of $C$. utilis grown with ammonium or nitrate as the nitrogen source. Also included are the $\mathrm{CO}_{2}$ yields from cultures growing on a mixture of glucose and formate with ammonium as the nitrogen source. The ${ }^{14} \mathrm{CO}_{2}$ yields from $\left[\mathrm{U}-{ }^{14} \mathrm{C}\right]$ glucose reflect the different biomass yields under the various growth conditions (Table 1). Growth with nitrate resulted in the lowest cell yield due to the requirement of NADPH for the reduction of nitrate to ammonium. The highest cell yield and thus the lowest $\mathrm{CO}_{2}$ yield was obtained during growth with ammonium on a mixture of glucose and formate (Bruinenberg et al., 1985a). This high cell yield as compared with growth on glucose alone is due to utilization of formate as an additional energy source, sparing glucose for assimilation. However, as pointed out by Bruinenberg $e t$ al. (1985a), formate cannot generate the NADPH required for biomass formation and therefore cannot eliminate the necessity to oxidize a fraction of glucose via the HMP pathway. The validity of this postulate is evident from Table 1 . Although less $\mathrm{CO}_{2}$ was produced from glucose during growth with formate, the yield of ${ }^{14} \mathrm{CO}_{2}$ from $\left[1-{ }^{14} \mathrm{C}\right]$ glucose was comparable to that during growth with glucose alone. The highest yields of ${ }^{14} \mathrm{CO}_{2}$ from $\left[1-{ }^{1+} \mathrm{C}\right]$ glucose were obtained during growth with nitrate. This is compatible with the high NADPH requirement for nitrate reduction. The low yield of ${ }^{14} \mathrm{CO}_{2}$ from $\left[6-{ }^{14} \mathrm{C}\right]$ glucose during growth with formate as 

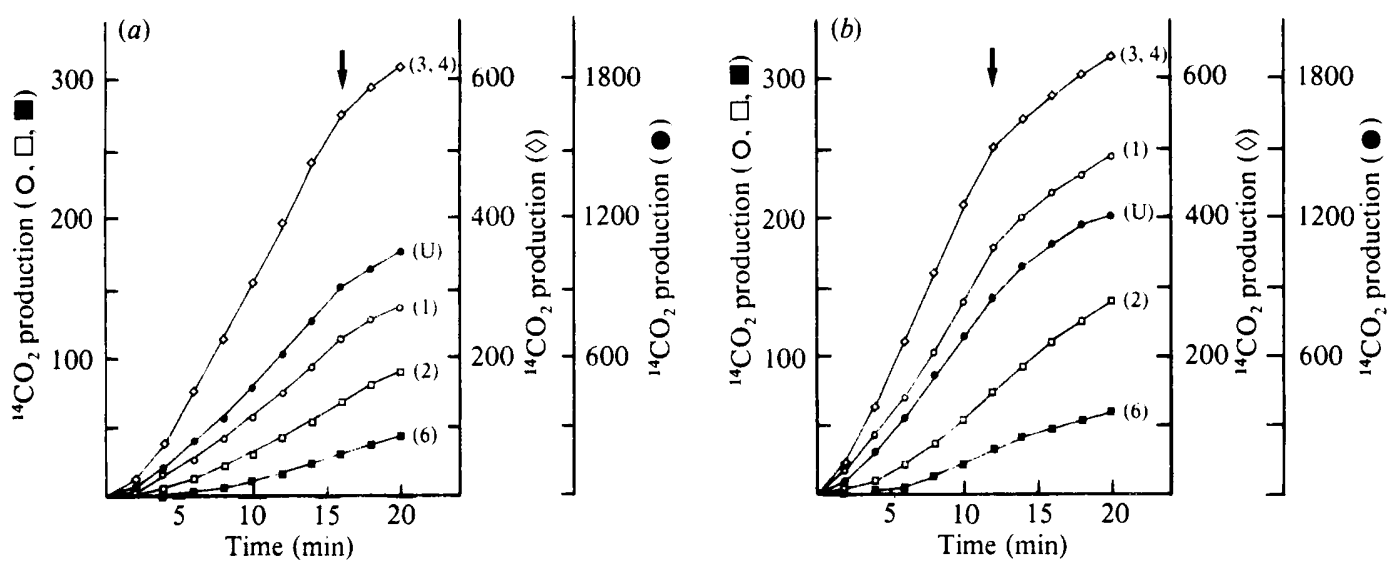

Fig. 2. Cumulative production of ${ }^{1+} \mathrm{CO}_{2}\left[\mathrm{nmol}(\mathrm{mg} \text { dry wt })^{-1}\right]$ during pulse-labelling experiments with $\left[\mathrm{U}-{ }^{1+} \mathrm{C}\right]-,\left[1^{-1+} \mathrm{C}\right]-,[2-1+\mathrm{C}]-,\left[3,4-^{-1+} \mathrm{C}\right]-$ and $\left[6^{-1+} \mathrm{C}\right]$ glucose in $5 \mathrm{ml}$ samples taken from glucose-limited chemostat cultures of $C$. utilis CBS 621 grown at $D=0 \cdot 1 \mathrm{~h}^{-1}$ with either ammonium $(a)$ or nitrate $(b)$ as the nitrogen source. Arrows indicate the time of depletion of glucose.

\section{Table $3 .{ }^{14} \mathrm{CO}_{2}$ production rates measured by pulse-labelling}

${ }^{14} \mathrm{CO}_{2}$ production rates $\left[\mathrm{nmol} \mathrm{CO}_{2} \mathrm{~min}^{-1}(\mathrm{mg} \text { dry } \mathrm{wt})^{-1}\right]$ during growth on glucose with ammonium or nitrate as nitrogen source were calculated from the data obtained in the pulse-labelling experiment shown in Fig. 2.

$\begin{array}{lccc}\text { Labelled substrate } & \text { Ammonium } & \text { Nitrate } & \begin{array}{c}\text { Ratio } \\ \text { Nitrate/ammonium }\end{array} \\ {\left[\mathrm{U}^{-14} \mathrm{C}\right] \text { Glucose }} & 67 \cdot 2 & 83.4 & 1.24 \\ {\left[1^{-14} \mathrm{C}\right] \text { Glucose }} & 8.6 & 16.9 & 1.97 \\ {\left[2-^{4} \mathrm{C}\right] \text { Glucose }} & 5.5 & 8.9 & 1.62 \\ {\left[3,4^{-14} \mathrm{C}\right] \text { Glucose }} & 40.2 & 46.4 & 1.15 \\ {\left[6-{ }^{-14} \mathrm{C}\right] \text { Glucose }} & 4.0 & 4.5 & 1.13\end{array}$

compared to growth with glucose alone confirms the low contribution of the tricarboxylic acid (TCA) cycle in glucose oxidation under these conditions. Under the experimental conditions the yield of biomass on glucose is maximal (Bruinenberg et al., 1985a). The ${ }^{14} \mathrm{CO}_{2}$ from $\left[6-{ }^{14} \mathrm{C}\right]-$ glucose, produced in the TCA cycle, may be attributed to assimilatory processes.

As can be seen in Table 2, application of the formulae of Wang \& Krackov (1962) and of Katz $\&$ Wood (1963) to the data of Table 1 shows that the HMP pathway is more active during growth with nitrate than during growth with ammonium. For growth with ammonium, and with formate as an additional energy source, a higher activity of the HMP pathway is calculated as compared to growth with glucose alone. The ratio of ${ }^{14} \mathrm{CO}_{2}$ yields from $\left[1-{ }^{14} \mathrm{C}\right]-$ and $\left[6-{ }^{14} \mathrm{C}\right]-$ glucose (Table 2), which frequently has been used as an indication for the activity of the HMP pathway, did not correlate with the values obtained with the formulae of Wang \& Krackov (1962) or of Katz \& Wood (1963).

Rates of ${ }^{14} \mathrm{CO}_{2}$ production from a pulse of labelled glucose to samples of steady-state cultures

The results described above clearly demonstrate that steady-state analysis of ${ }^{14} \mathrm{CO}_{2}$ production from specifically-labelled glucose can give at least qualitative information on changes in HMP pathway activities in response to environmental conditions. In an attempt to investigate the usefulness of pulse analysis, a less time-consuming method than steady-state analysis, we studied the rate of ${ }^{14} \mathrm{CO}_{2}$ production upon addition of glucose pulses to samples from steady-state cultures. A rather low concentration of glucose $(0.6 \mathrm{~mm})$ was used, in order to approximate steady-state conditions as closely as possible. The results obtained with samples from cultures growing with ammonium or nitrate as the nitrogen source are presented in Fig. 2. 
Both cultures showed the highest rate of ${ }^{14} \mathrm{CO}_{2}$ production with glucose labelled in carbon atoms 3 and 4 . The rate of $\mathrm{CO}_{2}$ production from positions 1,2 and 6 for growth with ammonium was much lower and decreased in the order of $1>2>6$. However, significant differences in $\mathrm{CO}_{2}$ production rates between the two cultures could be detected. The rate of ${ }^{14} \mathrm{CO}_{2}$ production from $\left[1-{ }^{14} \mathrm{C}\right]$ glucose by the culture grown with nitrate was much higher than that of the culture grown with ammonium.

The rates of ${ }^{14} \mathrm{CO}_{2}$ production, calculated from the slopes of the curves in Fig. 2, are shown in Table 3. Slopes were determined by linear regression of $\mathrm{CO}_{2}$ yields between $t=4 \mathrm{~min}$ and the time of glucose depletion, indicated by the arrows in Fig. 2. The overall rate of $\mathrm{CO}_{2}$ production in samples from the nitrate culture was 1.24 times that of the ammonium culture. The rates of ${ }^{14} \mathrm{CO}_{2}$ production from glucose labelled at positions 1 or 2 were disproportionally higher with nitrate as the nitrogen source, the ratio between nitrate and ammonium cells being 1.97 and 1.62 for $\left[1-{ }^{14} \mathrm{C}\right]$ - and $\left[2-{ }^{14} \mathrm{C}\right] \mathrm{glucose}$, respectively. Also the rates of ${ }^{14} \mathrm{CO}_{2}$ production from $\left[3,4-{ }^{14} \mathrm{C}\right]-$ and $\left[6-{ }^{14} \mathrm{C}\right]$ glucose were higher during growth with nitrate than during growth with ammonium. However, the ratios of ${ }^{14} \mathrm{CO}_{2}$ production rates from glucose labelled as above by cells grown on nitrate and ammonium were lower than the value of 1.24 determined with $\left[\mathrm{U}-{ }^{14} \mathrm{C}\right]$ glucose. If it is assumed that the production rate of ${ }^{14} \mathrm{CO}_{2}$ from $\left[5-{ }^{14} \mathrm{C}\right]$ glucose (commercially not available) is equal to the rate of $\mathrm{CO}_{2}$ production from $\left[2-{ }^{14} \mathrm{C}\right]$ glucose, the sum of the $\mathrm{CO}_{2}$ production rates from all specifically-labelled glucose molecules is $95-105 \%$ of the value observed with $\left[\mathrm{U}-{ }^{14} \mathrm{C}\right]$ glucose.

Although a very low concentration of glucose was used in these pulse-labelling experiments, the glucose consumption rates for growth with ammonium or nitrate were 77 and $100 \mathrm{nmol} \mathrm{min}^{-1}$ (mg dry wt) $)^{-1}$, respectively. This is almost five times as high as the glucose consumption rates during steady-state growth in the chemostat. The rate of ${ }^{14} \mathrm{CO}_{2}$ production from $\left[\mathrm{U}-{ }^{14} \mathrm{C}\right] \mathrm{glucose}$ in the pulse experiments was, however, only 1.2 times as high as that during steady-state growth in the chemostat.

\section{DISCUSSION}

Parameters affecting ${ }^{14} \mathrm{CO}_{2}$ production from specifically labelled glucose

The basic principles underlying radiorespirometric studies are simple and straight-forward. Oxidation of glucose via glycolysis and the TCA cycle will yield equimolar amounts of $\mathrm{CO}_{2}$ from glucose, labelled at positions 1 and 6 . In yeasts, any deviation in the yields of ${ }^{14} \mathrm{CO}_{2}$ from $\left[1-{ }^{14} \mathrm{C}\right]$ and $\left[6-{ }^{14} \mathrm{C}\right]$ glucose points to the participation of the hexose monophosphate (HMP) pathway in glucose metabolism, since the Entner-Doudoroff pathway is probably restricted to bacteria.

One of the major problems in radiorespirometric studies is the effect of randomization of the radioactive label over the various carbon atoms of the glucose molecule, as demonstrated by ${ }^{13} \mathrm{C}$ nuclear magnetic resonance studies in Saccharomyces cerevisiae (Den Hollander et al., 1979). Exchange of label from $C_{1}$ to $C_{6}$ occurs by rapid backward and forward reactions in the fructose-bisphosphate aldolase-triose-phosphate isomerase triangle in glycolysis. Similar processes may occur in the transaldolase and transketolase reactions of the HMP pathway (Katz \& Rognstad, 1967). Exchange of common intermediates of the HMP pathway and glycolysis will thus lead to rapid randomization of the administered label. In glucose-limited chemostat cultures of $C$. utilis, the situation is even more complex, due to the activity of fructose-1,6bisphosphatase (Bruinenberg et al., 1983a,b) which can cause additional randomization of the label.

Changes in the ratio of ${ }^{14} \mathrm{CO}_{2}$ yields from $\left[1-{ }^{14} \mathrm{C}\right]-$ and $\left[6-{ }^{14} \mathrm{C}\right]$ glucose have frequently been taken as an indication of changes in HMP pathway activities (see, e.g., Dawson et al., 1976). However, as pointed out by Gancedo \& Lagunas (1973), care should be taken in the interpretation of $\mathrm{C}_{1} / \mathrm{C}_{6}$ ratios. Indeed, the expected high activity of the HMP pathway during growth with nitrate coincides with a higher $\mathrm{C}_{1} / \mathrm{C}_{6}$ ratio of 2.5 as compared to 1.8 for growth with ammonium (Table 2). However, the high value (5.3) of the $\mathrm{C}_{1} / \mathrm{C}_{6}$ ratio for growth of $C$. utilis with glucose, formate and ammonium illustrates that a high $\mathrm{C}_{1} / \mathrm{C}_{6}$ ratio is not invariably correlated with a high relative contribution of the HMP pathway to glucose metabolism. As 
Table 4. Theoretical minima for the percentage of glucose oxidized in the HMP pathway

Values were calculated for growth on glucose with ammonium or nitrate as nitrogen source. The mode of operation of the HMP pathway (NADPH yield) and the contribution of NADP+-linked isocitrate dehydrogenase (isodh) were taken into account.

HMP pathway yielding per glucose 6-phosphate:

$\begin{aligned} 2 & \text { NADPH } \\ 6 & \text { NADPH } \\ 12 & \text { NADPH }\end{aligned}$

\begin{tabular}{|c|c|}
\hline \multicolumn{2}{|c|}{ Nitrate } \\
\hline+ isodh & -isodh \\
\hline$>100$ & $>100$ \\
\hline 38 & 46 \\
\hline 19 & 23 \\
\hline
\end{tabular}

compared to growth with glucose plus ammonium alone, only a slightly higher activity of the HMP pathway would be expected, since in the presence of formate as an additional energy source, more glucose will be incorporated into biomass. The yield of ${ }^{14} \mathrm{CO}_{2}$ from $\left[1-{ }^{14} \mathrm{C}\right]$ glucose is hardly affected by the degree of assimilation of glucose. The high ratio of 5.3 is due to the very low yield of ${ }^{14} \mathrm{CO}_{2}$ from $\left[6-{ }^{14} \mathrm{C}\right]$ glucose (Table 2). Hence, high ratios of $\mathrm{C}_{1} / \mathrm{C}_{6}$ may not only result from a relatively high activity of the HMP pathway, but may also be a reflection of the degree of incorporation of glucose into biomass.

\section{Steady-state analysis of HMP pathway activities}

In an earlier study (Bruinenberg et al., 1983a) we provided a model for the estimation of HMP pathway activities, based on the NADPH requirement for biosynthesis. These calculations cannot provide exact estimates but rather indicate the order of magnitude of the contribution of this pathway to glucose metabolism. Table 4 summarizes the theoretically required minimum values, taking into account the mode of operation of the HMP pathway and the possible contribution of the isocitrate dehydrogenase reaction to NADPH formation. It can be concluded that equation (1), and thus the formula of Wang \& Krackov (1962), cannot be applied to all our experimental data. In the case of growth with nitrate, an HMP pathway operating according to equation (1) cannot yield enough NADPH to cover the NADPH requirement for biosynthesis. Furthermore, as will be shown below, recycling in the HMP pathway does indeed occur, making the assumptions of Wang \& Krackov (1962) invalid. When the formula of Katz \& Wood (1963) is applied to our experimental data, a value of $7 \%$ is obtained for the contribution of the HMP pathway to glucose metabolism during growth with ammonium (Table 2). This is within the expected range of 3-14\% (Table 4). However, during growth with nitrate, the experimental value of $21 \%$ (Table 2) is much lower than the theoretically expected values of 38 $46 \%$ (Table 4). The low experimental value can only fit the theoretical requirement when the HMP pathway operates according to equation (4) and yields 12 NADPH per glucose 6phosphate oxidized. Since for such a mechanism no calculation methods are currently available, a further comparison of experimental and theoretical data is not possible. Nevertheless, despite these theoretical constraints, it can be concluded from the experimental data that during growth with nitrate the activity of the HMP pathway is approximately three times as high as during growth with ammonium. This value is in good accordance with the expected increase in flow of substrate carbon through the HMP pathway. On the basis of theoretical considerations (Bruinenberg et al., 1983a) the ratio between NADPH requirements per unit of biomass during growth with nitrate and ammonium, respectively, is calculated as 3.9.

From the radiorespirometric results it is evident that the increased activity of enzymes in the HMP pathway during growth with glucose plus nitrate, as compared to growth with glucose plus ammonium (Bruinenberg et al., 1983b), indeed reflects an increase in the flow of substrate carbon via this route. Furthermore, the contribution of the HMP pathway to glucose metabolism ( $7 \%$ and $21 \%$ with ammonium and nitrate, respectively; see Table 2$)$ is close to the theoretical minimum needed to cover the NADPH requirement for biomass formation $(2-7 \%$ and $19-23 \%$, respectively; see Table 4). Thus although mitochondria isolated from chemostat- 
grown $C$. utilis can oxidize NADPH with the formation of ATP (Bruinenberg et al., 1985b), it is unlikely that this process is quantitatively important in vivo.

\section{Pulse analysis of HMP pathway activities}

The results of pulse-labelling experiments with samples from steady-state cultures indicate that during growth with nitrate the HMP pathway is more active than during growth with ammonium. The rates of ${ }^{14} \mathrm{CO}_{2}$ production from labelled glucose can be used as an estimate for the relative contribution of the HMP pathway to glucose metabolism. The glucose consumption rates in cell suspensions grown with ammonium and nitrate as the nitrogen source were 77 and $100 \mathrm{nmol} \mathrm{min}-1$ (mg dry wt) $)^{-1}$, respectively. When the flow of glucose via the HMP pathway is defined as the difference in ${ }^{14} \mathrm{CO}_{2}$ production rates from $\left[1-{ }^{14} \mathrm{C}\right]$ - and $\left[6-{ }^{14} \mathrm{C}\right] \mathrm{glucose}$, the contribution of the HMP pathway to glucose metabolism for growth of $C$. utilis with glucose plus ammonium is $[(8.6-4) / 77] \times 100 \%=6 \%$ (see Table 3). For pulse-labelling experiments with cells grown with glucose plus nitrate, the relative contribution of the HMP pathway to glucose metabolism would then be $13 \%$. However, in this simple calculation the effect of recycling in the HMP pathway is neglected. Since for $\left[1^{14} \mathrm{C}\right]$ glucose the administered label is diluted by the recycled, unlabelled fructose 6-phosphate, production rates of ${ }^{14} \mathrm{CO}_{2}$ from this label will be lower, and therefore the HMP pathway activity will be underestimated. That recycling does occur can be concluded from the fact that the rate of ${ }^{14} \mathrm{CO}_{2}$ production from $\left[2-{ }^{14} \mathrm{C}\right] \mathrm{glucose}$ is higher than that from $\left[6-{ }^{14} \mathrm{C}\right]$ glucose. Since both labelled carbon atoms would be released in the TCA cycle very similar rates would be expected. Furthermore, the relative increase in ${ }^{14} \mathrm{CO}_{2}$ production from $\left[2-{ }^{14} \mathrm{C}\right]$ glucose for growth with nitrate as compared to growth with ammonium is higher than the relative increase in ${ }^{14} \mathrm{CO}_{2}$ production from $\left[6-{ }^{14} \mathrm{C}\right]$ glucose under these growth conditions (Table 3). This indicates that the degree of recycling in the HMP pathway is not constant and may vary in relation to the NADPH demand for biomass formation. It is difficult to include such variations in calculations.

\section{Steady-state analysis versus pulse analysis}

Since, as demonstrated above, the rate of NADPH production is adjusted to its rate of consumption in assimilation, it follows that physiologically significant data on the flow of carbon over the HMP pathway can only be obtained under conditions of balanced growth in the chemostat. Pulse analysis is not suitable in this respect because, as shown in this study, even the addition of a very low amount of glucose drastically changes the flow of substrate carbon.

The authors thank Prof. Dr J. G. Kuenen for stimulating discussions.

\section{REFERENCES}

Bruinenberg, P. M., van Dijken, J. P. \& Scheffers, W. A. $(1983 a)$. A theoretical analysis of NADPH production and consumption in yeasts. Journal of General Microbiology 129, 953-964.

Bruinenberg, P. M., van DiJken, J. P. \& SchefFers, W. A. $(1983 b)$. An enzymic analysis of NADPH production and consumption in Candida utilis CBS 621. Journal of General Microbiology 129, 965971.

Bruinenberg, P. M., Jonker, R., Van Dijken, J. P. \& SCHEFFERS, W. A. (1985a). Utilization of formate as an additional energy source by glucose-limited chemostat cultures of Candida utilis CBS 621 and Saccharomyces cerevisiae CBS 8066. Evidence for the absence of transhydrogenase activity in yeasts. Archives of Microbiology 142, 302-306.
Bruinenberg, P. M., van Dijken, J. P., Kuenen, J. G. \& Scheffers, W. A. $(1985 b)$. Oxidation of NADH and NADPH by mitochondria from the yeast Candida utilis. Journal of General Microbiology 131, 1043-1051.

Dawson, P. S. S., Okada, W. \& Steinhauer, L. P. (1976). Some comparative observations on the relative contributions of alternate pathways in the metabolism of glucose by Candida utilis. Canadian Journal of Microbiology 22, 996-1001.

Den Hollander, J. A., Brown, T. R., Ugurbil, K. \& Shulman, R. G. (1979). ${ }^{13} \mathrm{C}$ nuclear magnetic resonance studies of anaerobic glycolysis in suspensions of yeast cells. Proceedings of the National Academy of Sciences of the United States of America 76, 6096-6100. 
Gancedo, J. M. \& Lagunas, R. (1973). Contribution of the pentose-phosphate pathway to glucose metabolism in Saccharomyces cerevisiae : a critical analysis on the use of labelled glucose. Plant Science Letters 1, 193-200.

Harder, W., Visser, K. \& Kufnen, J. G. (1974). Laboratory fermenter with an improved magnetic drive. Laboratory Practice 23, 644-645.

Katz, J. \& Rognstad, R. (1967). The labeling of pentose phosphate from glucose $-1+\mathrm{C}$ and estimation of the rates of transaldolase, transketolase, the contribution of the pentose cycle, and ribose phosphate synthesis. Biochemistry 6, 2227-2247.

KATZ, J. \& WoOD, H. G. (1963). The use of $\mathrm{C}^{1+} \mathrm{O}_{2}$ yields from glucose- 1 and $-6-\mathrm{C}^{14}$ for the evaluation of the pathways of glucose metabolism. Journal of Biological Chemistry 238. 517-523.
Mian, F. A., Fencl, Z., Prokop, A., Mohagheghi, A \& FAZELI, A. (1974). Effect of growth rate on the glucose metabolism of yeast grown in continuous culture. Radiorespirometric studies. Folia microbiologica 19, 191-198.

Robertson, L. A. \& Kuenen, J. G. (1984). Aerobic denitrification - old wine in new bottles? Antonie van Leeuwenhoek 50, 525-544.

VerduYn, C., van DiJKen, J. P. \& Scheffers, W. A. (1984). Colorimetric alcohol assays with alcohol oxidase. Journal of Microbiological Methods 2, 1525.

WANG, C. H. (1972). Radiorespirometric methods. Methods in Microbiology 6B, 185-230.

Wang, C. H. \& Krackov, J. K. (1962). The catabolic fate of glucose in Bacillus subtilis. Journal of Biological Chemistry 237, 3614-3622. 